\title{
Design, synthesis, in silico studies and biological evaluation of 5-((E)-4-((E)-(substituted aryl/alkyl)methyl)benzylidene)thiazolidine-2,4-dione derivatives
}

\section{Harsh Kumar}

Maharshi Dayanand University Rohtak

\section{Aakash Deep}

Chaudhary Bansi Lal University

Rakesh Kumar Marwaha ( $\sim$ rkmarwaha.mdu@gmail.com )

Maharshi Dayanand University Rohtak

\section{Research article}

Keywords: Thiazolidin-2,4-dione; Synthesis; Antimicrobial; Antioxidant; Characterization

Posted Date: February 21st, 2020

DOI: https://doi.org/10.21203/rs.2.22295/v2

License: (c) (1) This work is licensed under a Creative Commons Attribution 4.0 International License.

Read Full License 


\section{Abstract}

Background: Looking at the extensive biological potential of thiazolidine-2,4-dione (TZD) moiety, a new series of thiazolidine-2,4-dione analogues was synthesized. Different spectral techniques (1H-NMR, IR, MS etc.) were used to confirm the chemical structures of the synthesized analogues. These synthesized compounds were screened for their antioxidant and antimicrobial potential. Results and discussion: The antimicrobial screening was carried out against selected strains of fungi and bacteria using serial tube dilution method. The antioxidant potential was assessed using stable 2,2-diphenyl-1-picrylhydrazyl (DPPH) free radical scavenging method. Further, the interaction between synthesized thiazolidine-2,4dione compounds and DNA gyrase was explored using molecular docking studies. Various ADME parameters were also studied to evaluate the drug likeness of the synthesized compounds. Conclusion: In antimicrobial evaluation, the compounds $4,9,11,12,13,15$ and 16 displayed promising activity against selected strains of microbes. Antioxidant evaluation found compound 6 having IC50 $=9.18 \mu \mathrm{g} / \mathrm{mL}$ to be the most potent compound in the series. The molecular docking study revealed compounds 4 (dock score $=-4.73$ ) and 7 (dock score $=-4.61$ ) with decent docking score, possess good interaction inside the ATP binding pocket of DNA gyrase and therefore can be used as lead structure for further optimizing into potent antimicrobial molecule.

\section{Introduction}

The increasing rate of microbial infection and development of drug resistance amongst different microbial strains are the major cause of worry for human life worldwide [1]. Some of these resistant strains, such as multidrug resistant staphylococcus aureus (MRSA) and vancomycin-resistant enterococci (VRE) are proficient of surviving the effects of most, if not all, antibiotics currently in use [2]. Emergence of new infectious ailments and development of multidrug resistance are amongst the biggest hurdles in the treatment of microbial infections and therefore imposes the finding of newer antimicrobial compounds [3]. Small heterocyclic rings having sulfur and nitrogen atoms like thiazolidine-2,4-dione (TZD) have been under study for a long time due to their synthetic variety and therapeutic relevance [4]. The TZD moiety is reported to possess extensive biological potential such as antifungal [5], analgesic, anti-inflammatory [6], hypoglycemic [7], antimalarial [8], antiproliferative [9], antitubercular [10], antioxidant [11], antiviral [12], hypolipidemic [13] and antibacterial [14-16] etc. The biological potential of TZD moiety is displayed in Fig. 1.

Expressive view of possible drug-receptor interaction can be a new rational method for drug design which can be explored using molecular docking studies. DNA gyrase is a vital enzyme of topoisomerases class that are involved in the regulation of topological transitions of DNA by the formation of negative supercoils. It is also involved in replication and transcription processes. Its inhibition causes DNA disruption which ultimately leads to cell death [17].

Poor pharmacokinetic properties of the drug molecules like absorption, distribution, metabolism and excretion (ADME) are amongst the major causes of failure during drug development process [18]. ADME 
properties are the critical determinants for the clinical success of the drug molecule which otherwise can be withdrawn from the market due to unexpected toxicity leading huge financial loss [19]. These studies can also help in optimizing a chemical compound with a certain pharmacological or biological activity to be orally active drug in humans [20].

Based on the data attained from literature survey, in the present study we hereby account the synthesis, antioxidant and antimicrobial potentials, molecular docking studies and ADME properties of thiazolidine2,4-dione derivatives.

\section{Results And Discussion}

\section{Chemistry}

The synthesis of TZD derivatives (1-20) were accomplished using the synthetic route depicted in Scheme 1. At first, 2-chloroacetic acid was treated with thiourea in conc. $\mathrm{HCl}$ to obtain TZD (I). Further, the reaction of (I) with terephthalaldehyde yielded 4-((2,4-dioxothiazolidin-5-ylidene) methyl) benzaldehyde (II).

Intermediate-II on further treatment with substituted anilines/amines yielded final 5-((E)-4-((E)-(substituted aryl/alkyl)methyl)benzylidene)thiazolidine-2,4-dione derivatives (1-20). The physicochemical characterization and spectral analysis of the synthesized derivatives are given in Table 1. The molecular structures of the synthesized derivatives (1-20) were established using elemental analysis and spectral studies [FT-IR $\left(\mathrm{KBr}, \mathrm{cm}^{-1}\right),{ }^{1} \mathrm{H}-\mathrm{NMR}\left(\mathrm{DMSO}-d_{6}, 400 \mathrm{MHz}, \delta \mathrm{ppm}\right)$ and Mass spectra]. The ${ }^{1} \mathrm{H}$-NMR spectra designated that the presence of multiplet signals between 6.52 and $8.28 \delta \mathrm{ppm}$ reflected the presence of aromatic protons in synthesized molecules. The presence of singlet(s) between 7.62-7.84 $\delta \mathrm{ppm}, 7.87-$ $8.80 \delta \mathrm{ppm}$ and 12.12-12.70 $\delta \mathrm{ppm}$ indicated the presence of $-\mathrm{CH}=,-\mathrm{CH}=\mathrm{N}$ and $-\mathrm{NH}$ groups, respectively. The compound 2 exhibited singlet (s) at $1.92 \delta \mathrm{ppm}$ due to the existence of $\mathrm{H}$ of $-\mathrm{NH}_{2}$ group. The appearance of singlet (s) at 2.08-2.33 $\delta \mathrm{ppm}$ in compounds $7,8,9$ and 10 revealed the existence of $\mathrm{CH}_{3}$ of $\mathrm{Ar}-\mathrm{CH}_{3}$. The existence of $\mathrm{OCH}_{3}$ of $\mathrm{Ar}-\mathrm{OCH}_{3}$ in the compounds, 15, 16 and 17 was confirmed by presence of singlet at 3.77-3.85 $\delta \mathrm{ppm}$. In compound $\mathbf{3} \mathrm{NH}$ of Ar-NH existence was confirmed by appearance of singlet at $10.61 \delta \mathrm{ppm}$. The compound 20 displayed multiplet at $1.23-1.69 \delta \mathrm{ppm}$ of $\mathrm{CH}_{2}$, triplet at $0.84 \delta \mathrm{ppm}$ of $\mathrm{CH}_{3}$ and multiplet at $3.66 \delta \mathrm{ppm}$ of $\mathrm{CH}_{2}$ adjacent to $\mathrm{CH}=\mathrm{N}$ due to the existence of dodecyl group. The compound 6 showed doublet signal at $4.77 \delta \mathrm{ppm}$ of $-\mathrm{CH}_{2}$ adjacent to furan ring, doublet signal at $6.30 \delta \mathrm{ppm}$ of $-\mathrm{CH}$ of furan ring at 3rd position, triplet signal at $6.42 \delta \mathrm{ppm}$ of $-\mathrm{CH}$ of furan ring at 4th position and doublet signal at $7.47 \delta \mathrm{ppm}$ of $-\mathrm{CH}$ of furan ring adjacent to $\mathrm{O}$ (oxygen) due to the existence of furfuryl group. In case of IR spectrum, the presence of bands at $3437-3286 \mathrm{~cm}^{-1}$, $3048-2919 \mathrm{~cm}^{-1}, 3197-3012 \mathrm{~cm}^{-1}, 1615-1548 \mathrm{~cm}^{-1}, 1522-1412 \mathrm{~cm}^{-1}, 1702-1610 \mathrm{~cm}^{-1}, 1747-1614 \mathrm{~cm}^{-1}$, and 618-594 $\mathrm{cm}^{-1}$ displayed the presence of $\mathrm{N}-\mathrm{H}, \mathrm{C}-\mathrm{H}$ (aliphatic), $\mathrm{C}-\mathrm{H}$ (aromatic), $\mathrm{C}=\mathrm{C}$ (methylene), $\mathrm{C}=\mathrm{C}$ (aromatic), $\mathrm{C}=\mathrm{N}, \mathrm{C}=\mathrm{O}$ and $\mathrm{C}-\mathrm{S}$ groups respectively in the synthesized analogues. The absorption bands around 1338-1224 $\mathrm{cm}^{-1}$ and $1165-1152 \mathrm{~cm}^{-1}$ corresponded to $\mathrm{C}-\mathrm{N}$ and $\mathrm{C}-\mathrm{C}$ stretching of compounds, respectively. Compounds $\mathbf{4}, \mathbf{5}$ and $\mathbf{1 4}$ displayed absorption bands of $\mathrm{C}-\mathrm{Cl}$ around $774-750 \mathrm{~cm}^{-1}$. Mass of the synthesized compounds exhibited $\mathrm{M}^{+}+1, \mathrm{M}^{+}$and $\mathrm{M}^{+}-1$ peaks. 


\section{Antimicrobial activity}

The in vitro antimicrobial screening studies of the synthesized TZD derivatives was evaluated by serial tube dilution procedure (Table 2, Fig. 2, 3 and 4). The antibacterial screening outcomes revealed that compounds 13 and 4 were moderately active against $S$. aureus with MIC value of $17.9 \mu \mathrm{M}$ and $18.2 \mu \mathrm{M}$, respectively. Further screening revealed that compounds 16 and 10 were moderately active against $B$. subtilis with MIC value of $18.5 \mu \mathrm{M}$ and $18.6 \mu \mathrm{M}$, respectively. Compound $13(\mathrm{MIC}=17.9 \mu \mathrm{M})$ and Compound $9(\mathrm{MIC}=18.6 \mu \mathrm{M})$ were found to be effective against $K$. pneumoniae. Compound $11(\mathrm{MIC}=$ $19.2 \mu \mathrm{M})$ possessed good activity against $E$. coli. Compound $\mathbf{5}(\mathrm{MIC}=18.5 \mu \mathrm{M})$ and compound $\mathbf{1 0}(\mathrm{MIC}=$ $18.6 \mu \mathrm{M})$ exhibited promising activity against $S$. typhi. The antifungal screening results revealed that the compounds $13(\mathrm{MIC}=17.9 \mu \mathrm{M})$ and $12(\mathrm{MIC}=16.1 \mu \mathrm{M})$ had good activity against $A$. niger and $C$. albicans respectively. The antibacterial screening results were found to be comparable with the standard drug (cefadroxil), whereas antifungal results of synthesized molecules exhibited superior activity against both the fungal strains i.e. A. niger and $C$. albicans except compound $\mathbf{2}$ in comparison to the standard drug (fluconazole). So, these synthesized compounds can be taken as lead structures and may further be optimized to yield new antimicrobial agents with better activity.

\section{Antioxidant evaluation}

The antioxidant efficacy of the newly synthesized derivatives was assessed by applying 2,2-diphenyl-1picrylhydrazyl (DPPH) radical scavenging method [21] using ascorbic acid as standard drug. 2,2-diphenyl1-picrylhydrazyl radical is a stable free radical which converts into a stable diamagnetic molecule by accepting an electron or a hydrogen radical. A strong absorption band at $517 \mathrm{~nm}$ is observed by methanolic solution of DPPH radical due to presence of an odd electron. DPPH radical reacts with appropriate reducing agent to produce new bond, which leads to change in the color of the solution. As the concentration of antioxidant compound increases in the solution, more electrons are taken up by the DPPH radical from the antioxidant molecules leading to loss in the color intensity of the solution. Such reactivity has been used to test the ability of compounds that can act as free radical scavengers. Reduction of the DPPH radicals has been monitored at $517 \mathrm{~nm}$ absorbance spectrophotometrically indicated by decrease in the intensity of color (Purple color) [22]. The $\mathrm{IC}_{50}$ value in $\mu \mathrm{g} / \mathrm{mL}$ was calculated for all the synthesized compounds. The antioxidant assay revealed all the synthesized compounds to be more potent than the standard drug. Further from the tested antioxidant results, compound 6 (IC50 $=9.18$ $\mu \mathrm{g} / \mathrm{mL}$ ) was found to be the most active and showed prominent activity results compared to standard drug. Results are displayed in Table 3 and Fig. 5.

\section{Molecular Docking Results}

DNA gyrase, a member of topoisomerases type II family has two genes i.e. GyrA and GyrB, which controls the topological state of DNA in cells [23]. During replication process DNA gyrase is required for maintenance of DNA topology during supercoiling of DNA through coupling of ATP hydrolysis by the 
GyrB subunit. DNA gyrase enzyme inhibition results in disruption of DNA synthesis in bacterial species leading to bacterial cell death [24].

Molecular docking study was carried out to analyze the binding affinity of the synthesized compounds with ATP binding pocket of DNA gyrase enzyme. The molecular docking study was carried out on GLIDE docking program. All the synthesized compounds were docked in the active site of the $S$. aureus GyrB ATPase domain (PDB: 3U2D) co-crystallized with 08B ligand. Binding affinity of compounds was compared using ATP as docking control. The results were investigated by comparing the docking score obtained from GLIDE (Table 4).

Binding affinity of the compounds was demonstrated in terms of binding energy, calculated in term of negative energy. Binding affinity is more when binding energy is less. Docking scores were shown as numerical value of interaction energy which is statistical evaluation function for displaying the results. Different visualization tools were used to visualize the 3D pose of the ligand interaction with receptor [25]. Molecular docking study revealed that the synthesized compounds exhibited good interaction with crucial amino acids of protein. The best-fitted compounds $\mathbf{4}$ and $\mathbf{7}$ showed the best docking scores of -4.73 and -4.61 , respectively in comparison to standard drug ofloxacin (docking score $=-5.107$ ) within the ATP binding pocket (Table 5). Ligand interaction diagram and binding mode of most active compounds 4, 7 and standard drug ofloxacin in the active site of S. aureus GyrB ATPase domain cocrystallized ligand 08B are shown in (Table 5, Figs. 7, 8 and 9). Docking studies revealed that antimicrobial compounds having better activity than the standard drug ofloxacin can be obtained by further optimizing the structure of the compounds $\mathbf{4}$ and $\mathbf{7}$.

\section{ADME results}

QikProp module of Schrodinger 2018-1 (Maestro version 11.5) was used for studying ADME parameters of the synthesized molecules. Around eleven pharmacologically significant and physically relevant parameters of the synthesized compounds (1-20) were studied. The ADME results of the synthesized TZD analogues 1-20 exhibited fairly good results within the recommended range of Qikprop module and in good agreement with Lipinski's rule of five which includes Molecular weight of the molecule (mol. MW = $<500$ ), Predicted water/gas partition coefficient (QPlogKp $=-8.0$ to-1.0), Percent human oral absorption (0 to 100$)$, donor HB (0.0 to -6.0$)$, (QPlogPw $=4.0$ to -45.0$)$, Predicted octanol/water partition coefficient (QPlogPo/w $=-2.0$ to -6.5 ), human oral absorption $(1,2$ or 3$)$, Predicted brain/blood partition coefficient (QPlogBB $=-3.0$ to -1.2$)$, accept HB $(2.0$ to -20.0$)$ and hence found these analogues as suitable drug candidates. The results of ADME studies are expressed in the Table 6.

\section{Structure activity relationship:}

From the antimicrobial and antioxidant evaluation studies following structure activity relationship can be drawn (Fig. 6): 
- The different substitution of amines/anilines used to synthesize the final derivatives of 5-((E)-4-((E)(substitutedaryl/alkyl)methyl)benzylidene)thiazolidine-2,4-dione played an important role in improving the antimicrobial and antioxidant activities. Substitution of electron releasing group methyl $\left(-\mathrm{CH}_{3}\right)$ at ortho and para position in the synthesized compound $\mathbf{9}$, increased the antibacterial potential against typhi and $K$. pneumoniae.

- Presence of Electron withdrawing group nitro (-NO2) at meta position enhanced antibacterial potential against pneumoniae and $S$. aureus as well antifungal activity against $C$. albicans and $A$. niger (Compound 4).

- Presence of electron withdrawing group fluoro (F) at ortho position of the synthesized compound 11, enhanced the antibacterial potential against coli whereas substitution of heterocyclic group furfuryl in the derived compound $\mathbf{6}$, improved the antioxidant potential. These molecules may further be used as lead compounds to derive more potent and less toxic novel antioxidant and antimicrobial agents.

\section{Experimental}

The chemicals of analytical grade were procured from commercial sources and were used for the synthesis without any purification. Open glass capillaries on a Stuart scientific SMP3 apparatus were used for determining melting point (m.p.) and reported uncorrected. Reaction progress was monitored by TLC glass plates of silica gel $\mathrm{G}$ for every synthetic step. $\mathrm{KBr}$ pellets were used for recording infrared (IR, $\mathrm{KBr}, \mathrm{cm}^{-1}$ ) on Bruker 12060280 (Software: OPUS 7.2.139.1294) spectrophotometer. Bruker Avance III 400 NMR spectrometer was used to determine ${ }^{1} \mathrm{H}$ spectra in appropriate deuterated solvents and using tetramethylsilane as internal standard and are expressed in parts per million $(\delta, \mathrm{ppm})$ downfield from internal standard. Mass spectra was obtained using Waters Micromass Q-ToF Micro instrument. CHN analyzer was used to perform elemental analysis.

\section{Synthetic steps of Scheme 1:}

\section{Step 1: Synthesis of thiazolidin-2,4-dione TZD(I):}

To a solution of chloroacetic acid $(0.06 \mathrm{~mol})$ in water $(15 \mathrm{~mL})$, thiourea $(0.06 \mathrm{~mol})$ in water $(15 \mathrm{~mL})$, acid was added and stirred till the occurrence of white precipitate. To the contents of flask, $6 \mathrm{~mL}$ of conc. $\mathrm{HCl}$ was added dropwise followed by refluxing for $10 \mathrm{~h}$. On cooling, needle shaped crystals of TZD (I) were obtained which were filtered, dried and recrystallized using methanol as solvent [6].

\section{Step 2: Synthesis of 4-((2,4-dioxo-1,3-thiazolidin-5-ylidene)methyl)benzaldehyde(II):}

To a solution of (I) $(0.03 \mathrm{~mol})$ and terephthalaldehyde $(0.03 \mathrm{~mol})$ in ethanol $(45 \mathrm{~mL}), 3 \mathrm{~mL}$ of piperidine $(0.0188 \mathrm{~mol})$ was added, stirred and refluxed for next $12 \mathrm{~h}$. Contents of flask were then poured on ice followed by acidification with acetic acid (glacial). Yellow coloured product of 4-((2,4-dioxo-1,3thiazolidin-5-ylidene)methyl)benzaldehyde (II) was obtained which was filtered, dried and further recrystallized using ethanol as solvent [26]. 
Step 3: Synthesis of various title compounds (1-20):

To the solution of compound II $(0.01 \mathrm{~mol})$ in methanol $(50 \mathrm{~mL})$, different substituted amines $(0.01 \mathrm{~mol})$ were added using catalytic amount of acetic acid (glacial) and refluxed for 4-18 h. The reaction mixture was then allowed to cool and finally recrystallized from methanol to give final compounds (1-20).

\section{In vitro antimicrobial evaluation}

The antimicrobial potential of the synthesized compounds was evaluated by serial tube dilution method [27] using fluconazole (antifungal) and cefadroxil (antibacterial) as standard drugs. Both Gram +ve \{MTCC-3160 (S. aureus), MTCC-441 (B. subtilis)\} and Gram -ve \{MTCC-3231 (S. typhi), MTCC-9024, (K. pneumoniae) and MTCC-443 (E. coli $)$ \} bacterial species were used in the study. The antifungal potential was evaluated against MTCC-281 (A. niger) and MTCC-227 (C. albicans) strains. Nutrient broth double strength I.P. (for bacteria) or sabouraud dextrose broth I.P. (for fungi) [28] nutrient media were used for antimicrobial potential. Stock solutions of the test and reference compounds were prepared in dimethyl sulfoxide. A control set was also used at the same dilutions with the test medium supplemented with dimethyl sulfoxide. Results were recorded in MIC after incubating the samples at $25 \pm 1^{\circ} \mathrm{C}$ (7 days) for $A$. niger, at $37 \pm 1{ }^{\circ} \mathrm{C}(24 \mathrm{~h})$ for bacteria and at $37 \pm 1^{\circ} \mathrm{C}(48 \mathrm{~h})$ for $C$. albicans, respectively. MIC was recorded for the tested compound as lowest concentration that showed no observable growth of microorganisms in the test tube.

\section{In vitro antioxidant assay}

The antioxidant evaluation of synthesized thiazolidine-2,4-dione derivatives was determined using stable 2, 2-diphenyl-1-picrylhydrazyl (DPPH) free radical scavenging model [29]. The diluted solution of synthesized compounds in methanol of $25 \mu \mathrm{g} / \mathrm{mL}, 50 \mu \mathrm{g} / \mathrm{mL}, 75 \mu \mathrm{g} / \mathrm{mL}$ and $100 \mu \mathrm{g} / \mathrm{mL}$ were prepared and equal amount of methanolic solution of DPPH $(0.0039 \%)$ was added followed by vigorous shaking. The above solution was then kept in dark for 30 minutes and absorbance of the solution was measured spectrophotometrically at $517 \mathrm{~nm}$ using UV-visible double beam spectrophotometer. The mean of at least three observations was taken as mean $\mathrm{IC}_{50}$ value in the data presented.

\section{Molecular Docking Study}

The target protein for thiazolidine-2,4-dione derivatives was identified through the literature. S. aureus GyrB ATPase (PDB Id: 3U2D) co-crystallized with 08B ligand, an excellent target for docking against $S$. aureus strain [30] was retrieved from Protein Data Bank(http://www.rcsb.org/pdb/home/home.do) to dock synthesized thiazolidine-2,4-dione compounds. Docking score was obtained from GLIDE software through targeted the ATP binding site by creating active site grid. The active site grid possessed the important amino acids which interact with ATP [31].

\section{Conclusion}


A series of thiazolidine-2,4-dione derivatives was designed, derived and then evaluated for its antioxidant and antimicrobial evaluations. The biological screening outcomes indicated that the molecules 4, 9, 11, $12,13,15$ and 16 showed promising activity against the selected strains of microbial species. Antioxidant evaluation found compound 6 having $\mathrm{IC}_{50}=9.18 \mu \mathrm{g} / \mathrm{mL}$ to be the most potent compound. Further, the molecular docking evaluation was carried out to find out the interaction between synthesized thiazolidine2,4-dione compounds with DNA gyrase protein indicated that compound $\mathbf{4}$ (Docking score $=-4.73$ ) and 7 (Docking score $=-4.61$ ) showed better potency within the ATP binding pocket by showing good dock score and hence can further be used as lead structures for rationally designing the antimicrobial molecule.

\section{Declarations}

\section{Conflict of interest:}

The authors have no conflict of interest.

\section{Author's Contributions}

Authors RKM and HK have designed, synthesized and performed the antimicrobial and antioxidant activities. AD has carried out the spectral analysis and helped in the structure interpretation of the synthesized compounds.

Authors' information (optional): Provided in the title page of manuscript

List of abbreviations- Not applicable

Ethics approval and consent to participate- Not applicable

Funding-Not applicable

\section{Acknowledgements}

The authors are thankful to Head, Department of Pharmaceutical Sciences, Maharshi Dayanand University, Rohtak, for providing necessary facilities to carry out this research work.

\section{References}

1. Prasad D, Kumar A, Shukla PK, Nath M (2011) Design, synthesis and antimicrobial evaluation of novel 2-aryl-thiazolidin-4-one derivatives. Org Med Chem Let

2. Moorthy P, Ekambaram SP, Perumal SS (2019) Synthesis, characterization and antimicrobial evaluation of imidazolyl thiazolidinedione derivatives. Arab J Chem 12(3):413-419

3. Keche AP, Hatnapure GD, Tale RH, Rodge AH, Birajdar SS, Kamble VM (2012) Novel pyrimidine derivatives with aryl urea, thiourea and sulfonamide moieties: synthesis, anti-infammatory and 
antimicrobial evaluation. Bioorg Med Chem Lett 22(10):3445-3448

4. Parekh NM, Juddhawala KV, Rawal BM (2013) Antimicrobial activity of thiazolyl benzene sulfonamide-condensed 2,4-thiazolidinediones derivatives. Med Chem Res 22:2737-2745

5. Desai NC, Satodiya HM, Rajpara KM, Joshi VV, Bhatt K, Vaghani HV (2014) Synthesis and evaluation of $N$-substituted thiazolidine-2,4-dione containing pyrazole as potent antimicrobial agents. Antiinfect Agents 12:85-94

6. Youssef AM, White MS, Villanueva EB, El-Ashmawy IM, Klegeris A (2010) Synthesis and biological evaluation of novel pyrazolyl-2,4-thiazolidinediones as anti-inflammatory and neuroprotective agents. Bioorgan Med Chem 18:2019-2028

7. Bhattarai BR, Kafle B, Hwang JS, Khadka D, Lee SM, Kang JS, Ham SW, Han IO, Park H, Cho H (2009) Thiazolidinedione derivatives as PTP1B inhibitors with antihyperglycemic and antiobesity effects. Bioorg Med Chem Lett 19:6161-6165

8. Sunduru N, Srivastava K, Rajakumar S, Puri SK, Saxena JK, Chauhan PMS (2009) Synthesis of novel thiourea, thiazolidinedione and thioparabanic acid derivatives of 4-aminoquinoline as potent antimalarials. Bioorg Med Chem Lett 19:2570-2573

9. Bozic B, Rogan J, Poleti D, Rancic M, Trisovic N, Bozic B, Uscumlic G (2017) Synthesis, characterization and biological activity of 2-(5-arylidene-2,4-dioxotetrahydrothiazole-3-yl)propanoic acid derivatives. Arab J Chem 10:S2637-S2643

10. Ponnuchamy S, Kanchithalaivan S, Kumar RR, Ali MA, Choon TS (2014) Antimycobacterial evaluation of novel hybrid arylidene thiazolidine-2,4-diones. Bioorg Med Chem Lett 24:1089-1093

11. Mishra G, Sachan N, Chawla P (2015) Synthesis and evaluation of thiazolidinedione-coumarin adducts as antidiabetic, anti-inflammatory and antioxidant agents. Lett Org Chem 12:429-445

12. Shaikh FM, Patel NB, Sanna G, Busonera B, Colla PL, Rajani DP (2015) Synthesis of some new 2amino-6-thiocyanato benzothiazole derivatives bearing 2,4-thiazolidinediones and screening of their in vitro antimicrobial, antitubercular and antiviral activities. Med Chem Res 24:3129-3142

13. Iqbal AKM, Khan AY, Kalashetti MB, Belavagi NS, Gong YD, Khazi IAM (2012) Synthesis, hypoglycemic and hypolipidemic activities of novel thiazolidinedione derivatives containing thiazole/triazole/oxadiazole ring. Eur J Med Chem 53:308-315

14. Sindhu J, Singh H, Khurana JM, Sharma C, Aneja KR (2015) Multicomponent domino process for the synthesis of some novel 5-(arylidene)-3-((1-aryl-1 H-1,2,3-triazol-4-yl)methyl)-thiazolidine-2,4-diones using PEG-400 as an efficient reaction medium and their antimicrobial evaluation. Chin Chem Lett 26:50-54

15. Juddhawala KV, Parekh NM, Rawal BM (2011) Synthesis and antibacterial activities of N-chloro aryl acetamide substituted thaizole and 2,4-thazolidinedione derivatives. Arch Appl Sci Res 3(5):540-548

16. Malik N, Prasad DN (2012) Synthesis and antimicrobial evaluation of N-Substituted-5-benzylidene2,4-thiazolidinedione derivatives. Iran J Pharm Sci 8(3):209-214

17. Perumal P, Pandey VP, Parasuraman P (2014) Docking studies on some novel piperidine analogues against DNA gyrase enzyme. Inventi Rapid Molecular Modeling. 1:1-4 
18. Wang J, Urban L (2004) The impact of early ADME profiling on drug discovery and development strategy. Drug Discov World Fall 5:73-86

19. Li AP (2001) Screening for human ADME/Tox drug properties in drug discovery. Res Focus 6(7):357366

20. Sharma D, Kumar S, Narasimhan B, Ramasamy K, Lim SM, Shah SAA, Mani V (2019) 4-(4-Bromophenyl)-thiazol-2-amine derivatives: synthesis, biological activity and molecular docking study with ADME profile. BMC Chem 13(60):1-16

21. Sugiharto S, Yudiartiz T, Isroli I (2016) Assay of antioxidant potential of two filamentous fungi isolated from the indonesian fermented dried cassava. Antioxidants 5:1-6

22. Redon J, Oliva MR, Tormos C, Giner V, Chaves J, Iradi A, Saez GT (2003) Antioxidant activities and oxidative stress by products in human hypertension. J Hypertens 1(1): 1096-1109

23. Wang JC (2009) Untangling the double helix: DNA entanglement and the action of the DNA topoisomerases. Cold Spring Harbor, New York

24. Maxwell A, Lawson DM (2003) The ATP binding site of type II topoisomerases as a target for antibacterial drugs. Curr Top Med Chem 3:283-303

25. Bassyouni F, El Hefnawi M, El Rashed A, Rehim MA (2017) Molecular modeling and biological activities of new potent antimicrobial, anti-inflammatory and anti-nociceptive of 5-nitro indoline-2one derivatives. Drug Des 6(2):1-6

26. Chinthala Y, Domatti AK, Sarfaraz A, Singh SP, Arigari NK, Gupta N, Satya SKVN, Kumar JK, Khan F, Tiwari AK, Grover P (2013) Synthesis, biological evaluation and molecular modeling studies of some novel thiazolidinediones with triazole ring. Eur J Med Chem 70:308-314

27. Cappuccino JC, Sherman N (1999) Microbiology-a laboratory manual. Addison Wesley, California, pp 263

28. Pharmacopoeia of India, vol.-I, 2007. Controller of publication, ministry of health department, Govt. of India, New Delhi, 37

29. Koppireddi S, Komsani JR, Avula S, Pombala S, Vasamsetti S, Kotamraju S, Yadla R (2013) Novel 2(2,4-dioxo-1,3-thiazolidin-5-yl)acetamides as antioxidant and/or anti-inflammatory compounds. Eur J Med Chem 66:305-313

30. Jas MJS, Marimuthu G, Prithivirajan B (2019) Hydrazone Analogues: Molecular Modeling, Synthesis, In- vivo Anti-Nociceptive Activity and in-vitro Antimicrobial Activity. Egypt J Chem 62(8):1441 - 1450

31. Singh J, Kumar M, Mansuri R, Sahoo GC, Deep A (2016) Inhibitor designing, virtual screening and docking studies for methyltrans-ferase: a potential target against dengue virus. J Pharm Bioallied Sci $8(3): 188-94$

\section{Tables}

Due to technical limitations, full-text HTML conversion of the manuscript tables could not be completed. However, the manuscript can be downloaded and accessed below. 
Figures

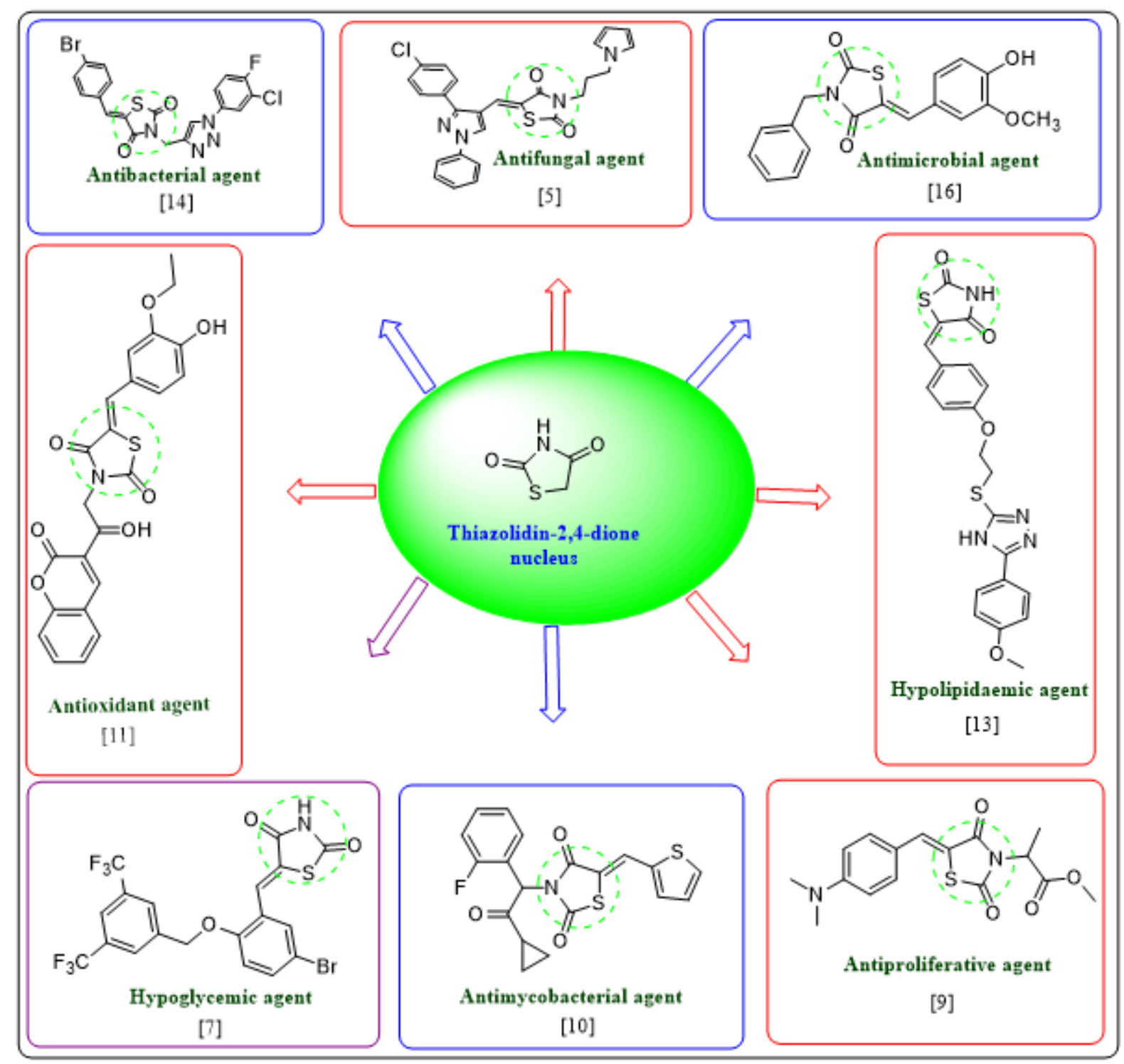

Figure 1

Biological potential of thiazolidin-2,4-dione moiety. 


\section{Antibacterial Screening (Gram Negative)}

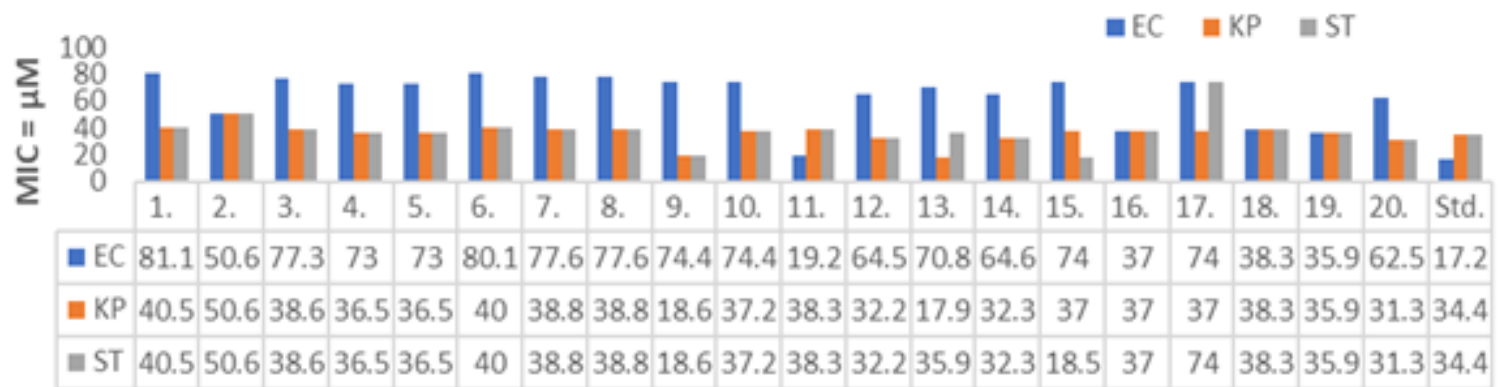

Compounds

Figure 2

Antibacterial screening results against Gram negative species

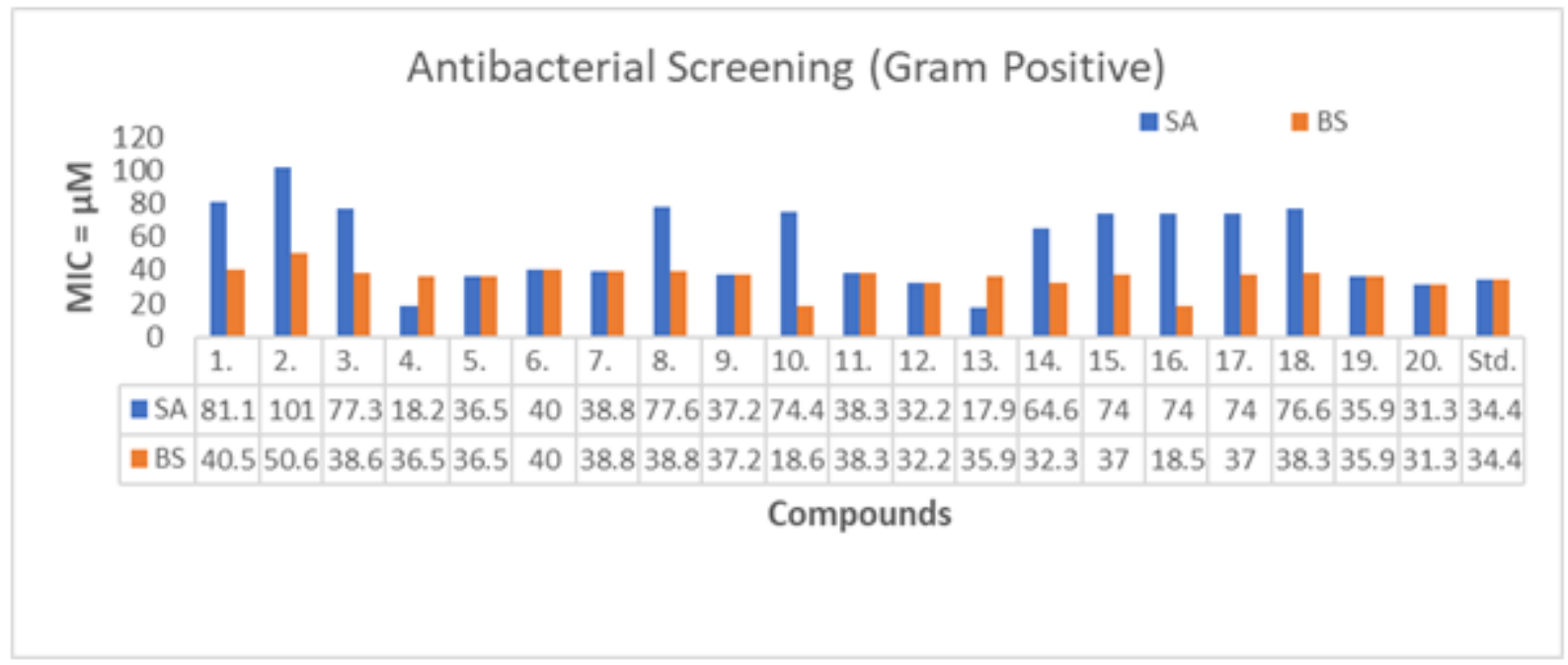

Figure 3

Antibacterial screening results against Gram positive species 


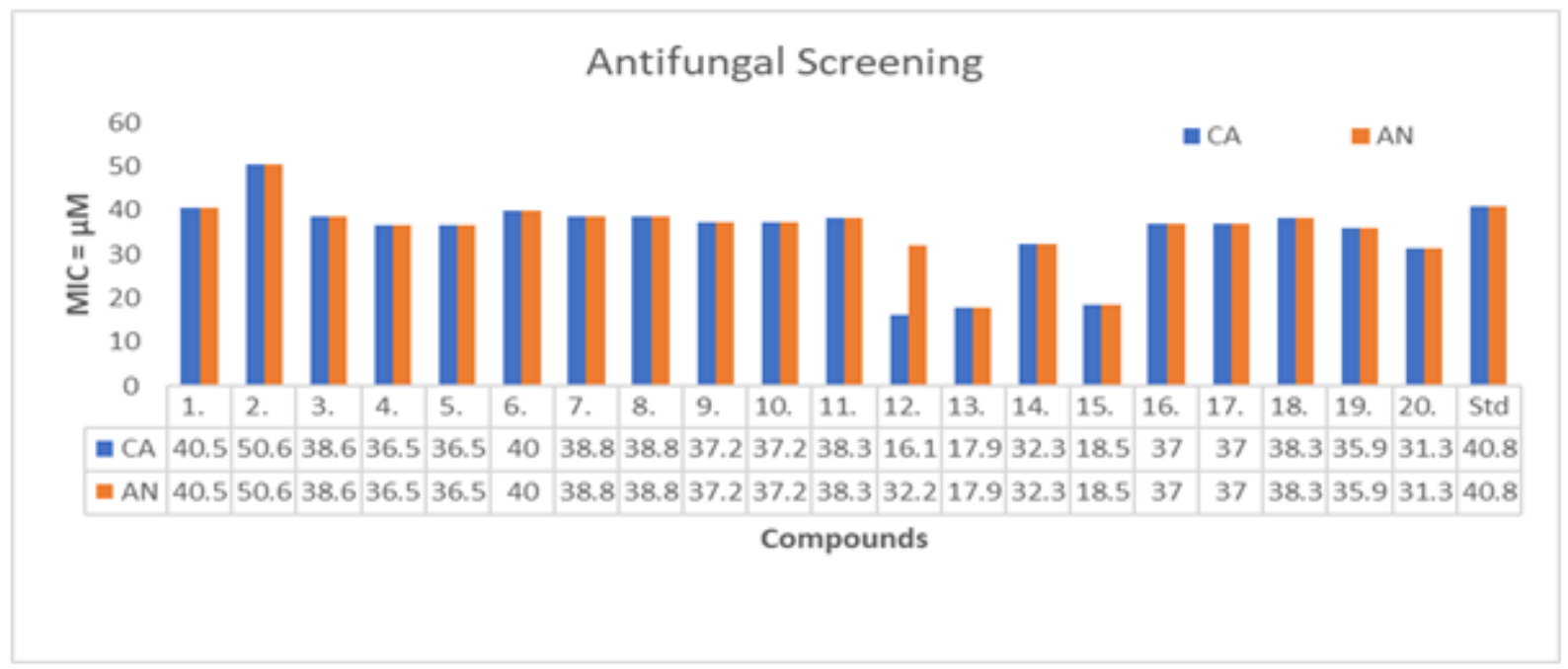

Figure 4

Antifungal screening results against fungal species

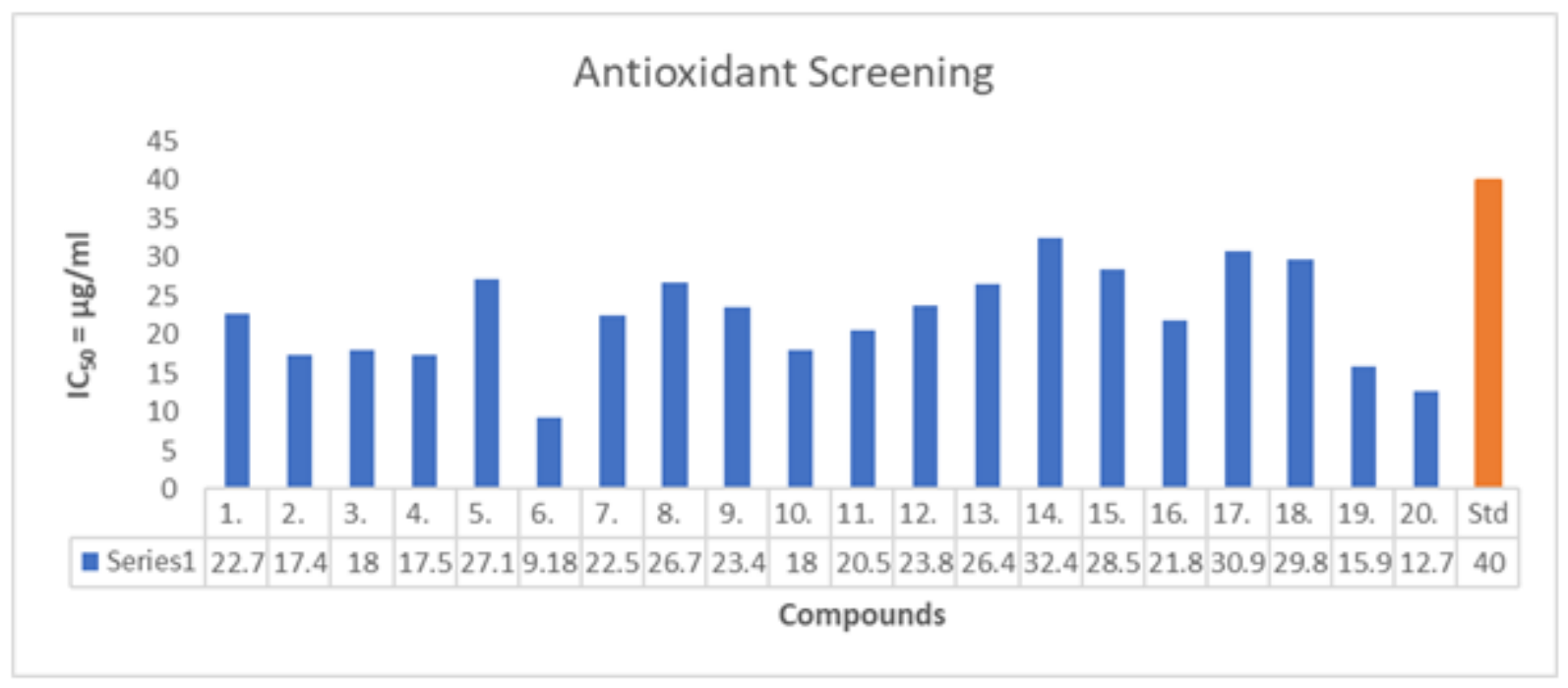

Figure 5

Antioxidant Evaluation of synthesized compounds using ascorbic acid as standard 


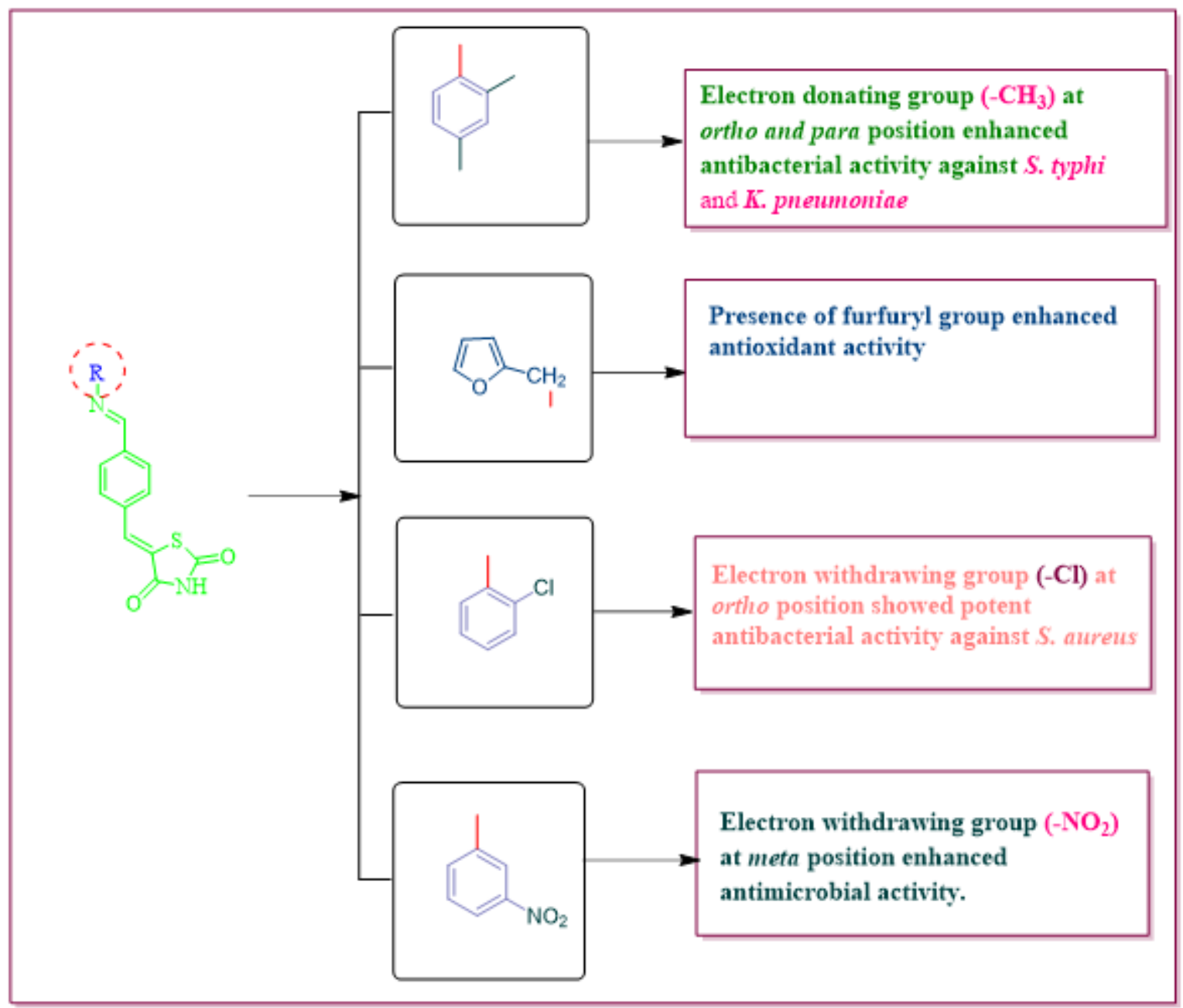

\section{Figure 6}

Structure activity relationship of synthesized compounds

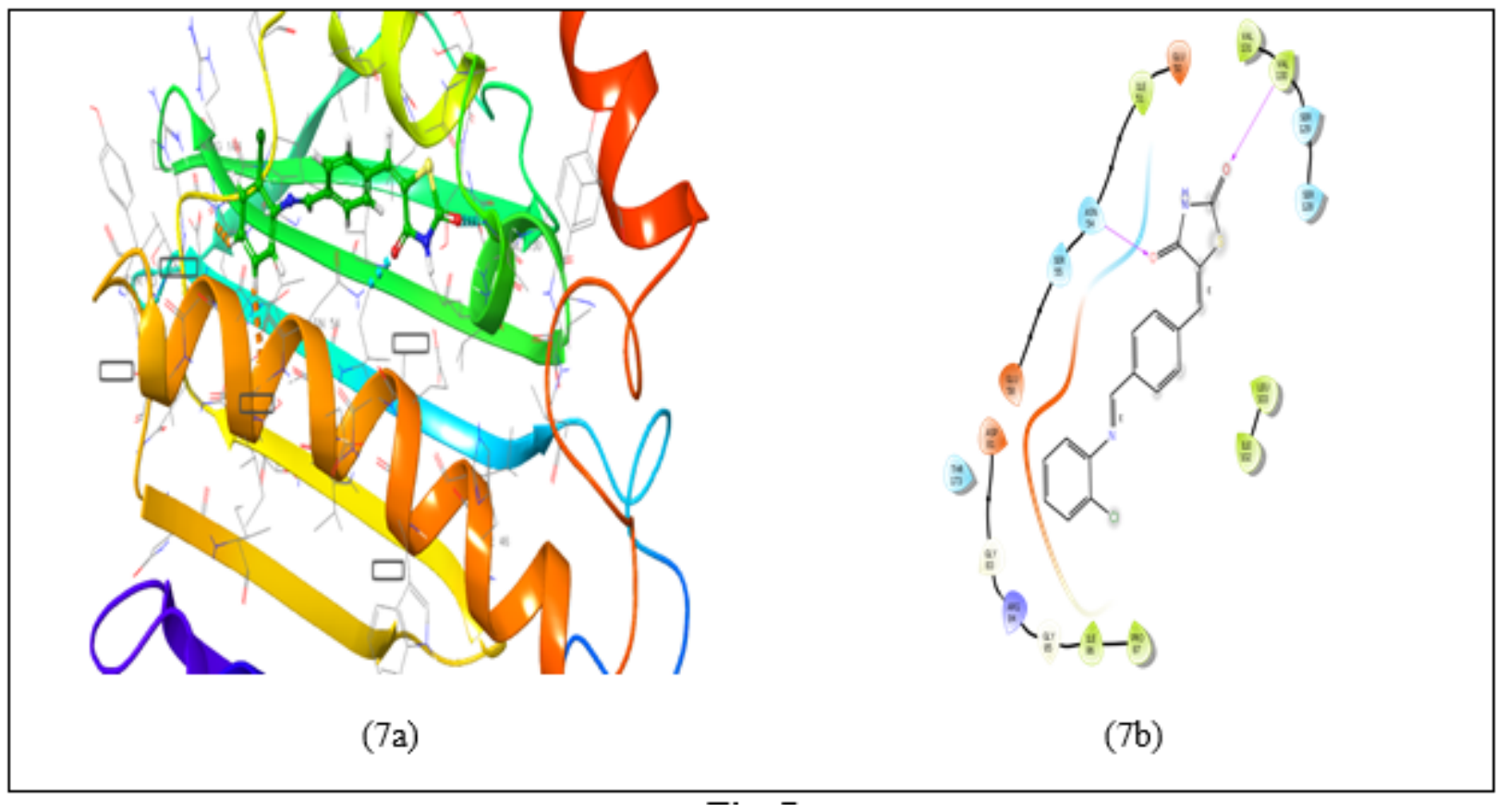


Figure 7

Interaction of compound 4 and 4-bromo-5-methyl-N-[1-(3-nitropyridin-2-yl)piperidin-4-yl]-1H-pyrrole-2carboxamide within the active pocket of S. aureus GyrB ATPase domain protein and interacting amino acid in 3D (7a) and 2D (7b) view

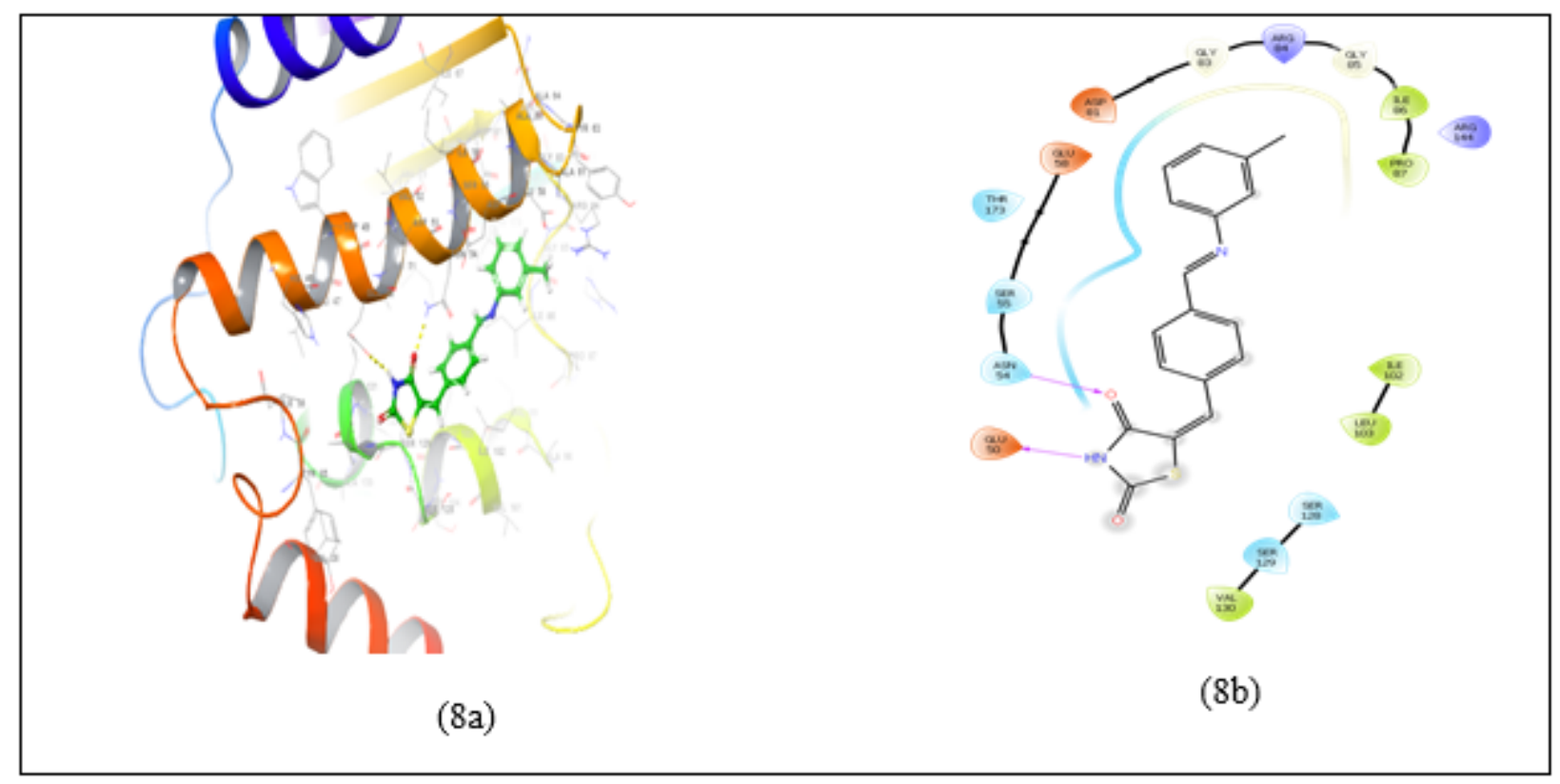

\section{Figure 8}

Interaction of compound 7 and 4-bromo-5-methyl-N-[1-(3-nitropyridin-2-yl)piperidin-4-yl]-1H-pyrrole-2carboxamide within the active pocket of S. aureus GyrB ATPase domain protein and interacting amino acid in 3D (8a) and 2D (8b) view

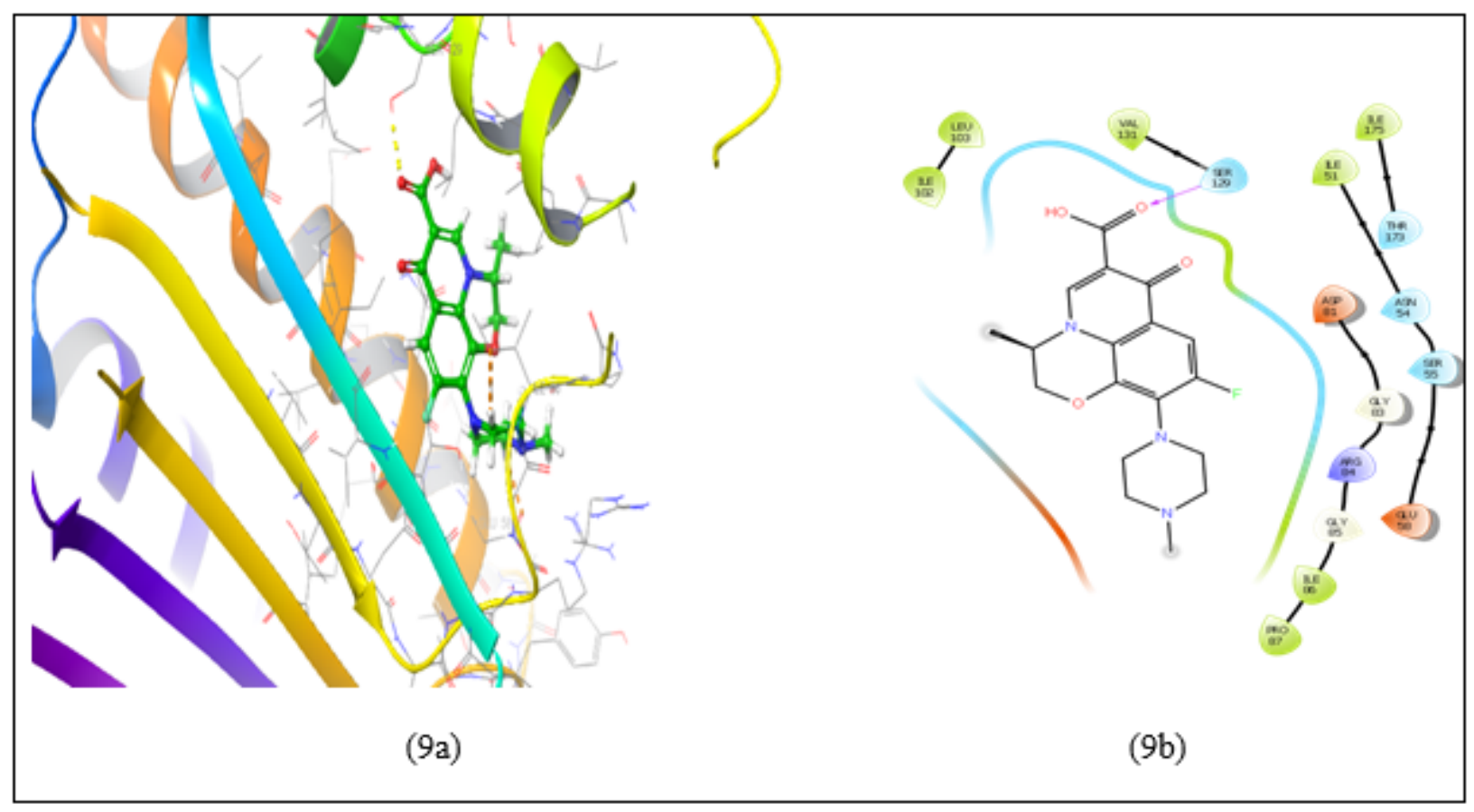

Figure 9 
Interaction of standard compound ofloxacin and 4-bromo-5-methyl-N-[1-(3-nitropyridin-2-yl)piperidin-4yl]-1H-pyrrole-2-carboxamide within the active pocket of S. aureus GyrB ATPase domain protein and interacting amino acid in 3D (9a) and 2D (9b) view

\section{Supplementary Files}

This is a list of supplementary files associated with this preprint. Click to download.

- Revisedgraphicalabstract.pdf

- RevisedTables.pdf

- Scheme1.jpg 